\title{
A NEW METHOD TO DETERMINE MAINTENANCE AND REPAIR ACTIVITIES AT NETWORK-LEVEL PAVEMENT MANAGEMENT USING FALLING WEIGHT DEFLECTOMETER
}

\author{
Amir KAVUSSI ${ }^{\mathrm{a}}$, Mojtaba ABBASGHORBANI ${ }^{\mathrm{a}}$, Fereidoon MOGHADAS NEJAD ${ }^{\mathrm{b}}$, \\ Armin BAMDAD ZIKSARI ${ }^{\mathrm{c}}$ \\ aDepartment of Civil and Environmental Engineering, Tarbiat Modares University, Tehran, Iran \\ ${ }^{b}$ Department of Civil and Environmental Engineering, Amirkabir University of Technology, Tehran, Iran \\ ${ }^{c}$ Technical and Soil Mechanics Laboratory of Ministry of Road and Urban Development, Tehran, Iran
}

Received 01 Feb 2015; accepted 08 Jun 2015

\begin{abstract}
Pavement condition assessment at network level requires structural evaluation that can be achieved using Falling Weight Deflectometer (FWD). Upon analysing FWD data, appropriate maintenance and repair methods (preservation, rehabilitation or reconstruction) could be assigned to various pavement sections. In this study, Structural Condition Index $(S C I)$, defined as the ratio of Effective Structural Number $\left(S N_{e f f}\right)$ to Required Structural Number $\left(S N_{\text {req }}\right)$, was used to determine if a pavement requires preservation or rehabilitation works (i.e. preservation $S C I>1$, rehabilitation $S C I<1)$. In addition to FWD deflection data, SCI calculation requires pavement layer thicknesses that is obtained using GPR with elaborated and time consuming works. In order to reduce field data collection and analysis time at networklevel pavement management, SCI values were calculated without having knowledge of pavement layer thicknesses. Two regression models were developed based on several thousand FWD deflection data to calculate $S N_{\text {eff }}$ of pavements and resilient modulus $\left(M_{R}\right)$ of their subgrades. Subgrades $M_{R}$ values together with traffic data were then used to calculate $S N_{\text {req. }}$. Statistical analysis of deflection data indicated that Area under Pavement Profile (AUPP) and the deflection at distance of $60 \mathrm{~cm}$ from load center $\left(D_{60}\right)$ parameters showed to have strong correlation with $S N_{\text {eff }}$ and $M_{R}$ respectively. The determination coefficients of the two developed models were greater than those of previous models reported in the literature. The significant result of this study was to calculate $S N_{\text {eff }}$ and $M_{R}$ using the same deflection data. Finally, implementation of the developed method was described in determining appropriate Maintenance and Repair (M\&R) method at network level pavement management system.
\end{abstract}

Keywords: Falling Weight Deflectometer (FWD), Structural Condition Index (SCI), Maintenance and Repair (M\&R) method, network-level pavement management, structural assessment, subgrade $M_{R}$.

\section{Introduction}

Pavement Management System (PMS) is implemented at network and project levels. At network level management, detailed data with high accuracies are not required. At this level, the type of Maintenance and Repair (M\&R) methods and required budget are determined for a road network. Pavements will then be assessed more accurately for specific M\&R method at project level. There are several categories of M\&R methods (Fig. 1) including pavement preservation, rehabilitation, and reconstruction (Pavement Interactive 2010). The most significant feature of a pavement is its structural condition, specifying either M\&R preservation or rehabilitation methods. Structurally weak pavements require rehabilitation or reconstruction works, which are costly and time consuming. For preservation works, minor road works and low cost preventive maintenance methods (e.g. fog seal, slurry seal, chip seal and hot in-place recycling) will be applied. Determination of distinction level between preservation and rehabilitation/reconstruction works is of great importance. Falling Weight Deflectometer (FWD) can be used to assess pavement structural condition and determine if a pavement requires preservation or rehabilitation. Figure 1 shows a general overview of the various maintenance level (Chowdhury et al. 2012).

Structural Condition Index $(S C I)$ based on FWD data is used to decide on the appropriate M\&R method (Shahin 2005; Zhang et al. 2003; Kim et al. 2013). SCI is the ratio between Effective Structural Number $\left(S N_{\text {eff }}\right)$ and Required Structural Number $\left(S N_{\text {req }}\right)($ Eqn (1)). These parameters were recommended by AASHTO to design pavement structure (AASHTO 1993):

$$
S C I=\frac{S N_{e f f}}{S N_{\text {req }}} .
$$

Corresponding author: Amir Kavussi

E-mail:kavussia@modares.ac.ir 


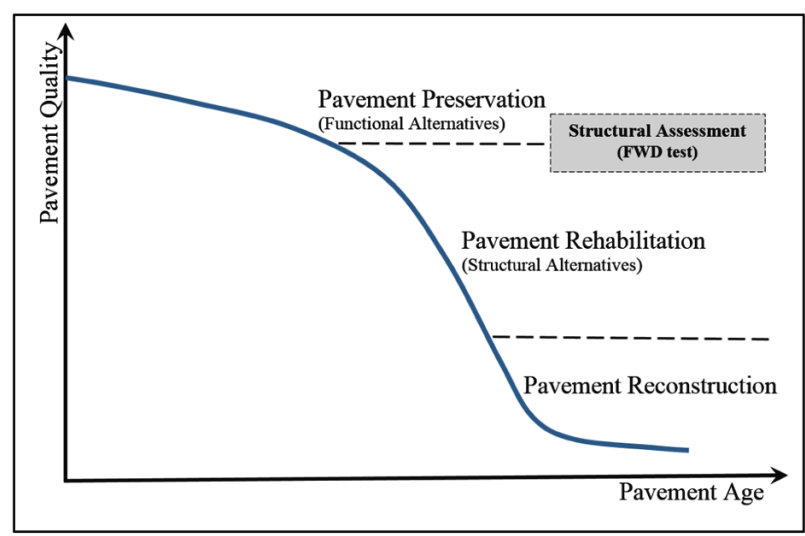

Fig. 1. Categories of various required M\&R activities versus pavement life

If $S C I \geq 1$, the pavement will have enough load bearing capacity to sustain traffic loading and only preservation activities will be required. If $S C I<1$, the pavement is structurally weak and requires rehabilitation or reconstruction (Stubstad et al. 2012; Bryce et al. 2013). $S N_{\text {eff }}$ describes bearing capacity of the existing pavement including aspht, base and subbase layers on top of the subgrade. $S N_{\text {req }}$ represents the required load bearing capacity of pavements regardless of the existing pavement condition.

The total pavement thickness and FWD deflection data are used in AASHTO (1993) rehabilitation procedure to determine $S N_{\text {eff }}$ of pavement and $M_{R}$ of subgrade (AASHTO 1993). The analysis initiates by a trial and error procedure to find subgrade deflection. $S N_{\text {eff }}$ is then determined using pavement effective modulus $\left(E_{P}\right)$ and the total pavement thickness. In addition, $S N_{\text {req }}$ is calculated using pavement design life traffic and the subgrade resilient modulus $\left(M_{R}\right)$ determined from FWD deflection data. Based on AASHTO pavement design method, both $S N_{\text {eff }}$ and $S N_{\text {req }}$ require deflection data and total thickness of pavement, which must be determined in the field (AASHTO 1993). Structural evaluation of pavements at network level is associated with several complications, summarized below:

1. Analysis of deflection data needs knowledge of layer thicknesses that is measured either using nondestructive equipment such as Ground Penetrating Radar (GPR) or destructive methods such as core drilling and pit boring of pavements. Both approaches are time consuming and require sophisticated works.

2. Data analysis in AASHTO method requires elaborated back-calculation works, which are complicated and time consuming.

3 . The main purpose of network level pavement management is to determine the type of appropriate M\&R methods requiring annual budget dedication, so that large amounts of data with high accuracies are not required.
The aim of this research was to solve the outlined problems without having knowledge of pavement thickness. With this regard, two regression models were analysed to predict $S N_{\text {eff }}$ and $M_{R}$ of subgrade based on Deflection Basin Parameters (DBP). The $M_{R}$ of the subgrade together with traffic data and reliability level are used to calculate $S N_{\text {req }}$ at the point where $S N_{\text {eff }}$ has already been calculated. These two $S N S$ are then used to calculate $S C I$ values in homogenous pavement sections and determine the distinction level between functional and structural alternatives at road network.

\section{Deflection basin parameters}

Deflection basin is a profile formed from deflections data determined from the FWD device as it is shown in Figure 2.

With reference to this figure, it is noted that the largest portion of basin variation occurred near the loading center. Thus, parameters extracted from this part of basin can truly be used to detect changes in pavement structural capacity. Deflection Basin Parameters (DBPs), reported in Table 1, are the most frequently used equations for FWD data analysis. Among various parameters shown in Table 1, central deflection $\left(D_{0}\right)$ is the most significant parameter used in pavement evaluation (both at network and project levels). This parameter defines the pavement and subgrade behaviour (Dasari 2013). It is also utilized to divide pavement into homogenous structural sections. Parameters such as Base Layer Index ( $B L I)$, Base Damage Index $(B D I)$ and Base Curvature Index $(B C I)$ are useful for structural assessment of asphalt, base and subbase/ subgrade layers, respectively (Aavik 2003). The AREA parameter in Table 1 determines the relative structural condition of pavement to subgrade and Area Under Pavement Profile $(A U P P)$ represents condition of upper portion of pavement (Horak et al. 2009).

\section{Research methodology}

The Database used in this research were taken from several main roads in Khuzestan province in south of Iran.

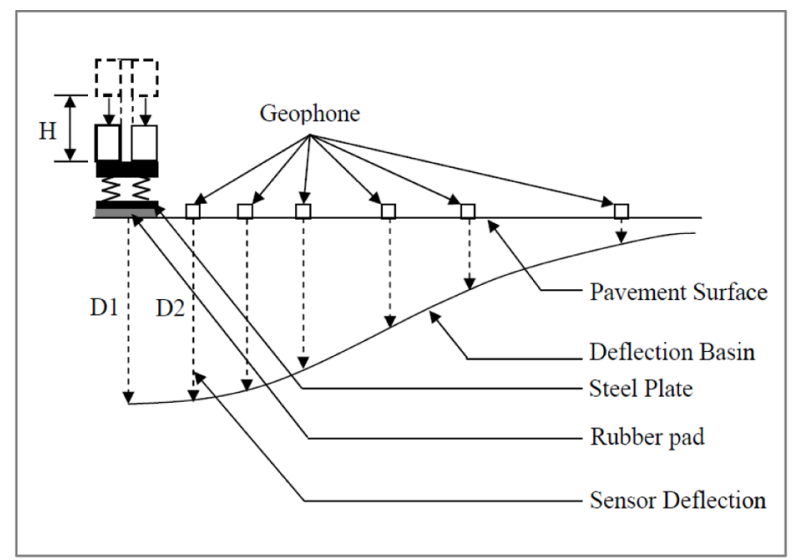

Fig. 2. Pavement deflection basin resulted from FWD device 
Table 1. Deflection basin parameters (DBPs) (Horak et al. 2009)

\begin{tabular}{c|c|l}
\hline Parameter & Equation & \multicolumn{1}{c}{ Description } \\
\hline$D_{\max }$ & Central deflection & Pavement Structural evaluation and pavement sectioning \\
\hline$B L I$ & $B L I=D_{0}-D_{200}$ & Structural assessment of asphalt layer \\
\hline$B D I$ & $B D I=D_{300}-D_{600}$ & Structural assessment of base layer \\
\hline$B C I$ & $B C I=D_{600}-D_{900}$ & Structural assessment of subbase and subgrade \\
\hline$A R E A$ & $A R E A=6\left(1+2 \frac{D_{300}}{D_{0}}+2 \frac{D_{600}}{D_{0}}+\frac{D_{900}}{D_{0}}\right)$ & Structural assessment of pavement and subgrade \\
\hline$A U P P$ & $A U P P=\left(\frac{5 D_{0}-2 D_{300}-2 D_{600}-D_{900}}{2}\right)$ & Structural assessment of upper portion of pavement \\
\hline
\end{tabular}

These included 2453 FWD (Dynatest) deflection basins and corresponding thicknesses using GPR. The data were collected using Dynatest FWD Type 9000 and Mala GPR Type $1 \mathrm{GHz}$ ground couple. Table 2 reports the statistical analysis of the data used in this research.

As it can be seen from Table 2, the database showed a good scattering in measured parameters (deflection and thickness). FWD central deflections were adjusted to $20^{\circ} \mathrm{C}$ and were normalized to stress of $570 \mathrm{kPa}$ to simulate the loading of half-standard axle load. Temperature correction factors were applied based on AASHTO (1993) design guide for central deflections. To eliminate the effect of temperature on DBPs (particularly at AREA, $A U P P$ and $B L I$ parameters), the deflections at the distances of 30, 60 and $90 \mathrm{~cm}$ from the loading center were adjusted using MODULUS program method. Table 3 reports the adjustment factors of the above deflections as percentage of temperature correction factor from the central deflection. As it can be seen in this table, the effect of temperature on deflections increased as a result of increasing thicknesses of asphalt layers. If the thickness of asphalt layer is less than $75 \mathrm{~mm}$, no temperature correction will be required.

Prior to calculating DBPs, the first four FWD deflections (up to $90 \mathrm{~cm}$ ) were adjusted to temperature of $20{ }^{\circ} \mathrm{C}$. The role of temperature adjustment is of great importance in calculating $B L I$. It can be negative if temperature correction factor is just applied to the central deflection (adjusted central deflection is less than deflection at $30 \mathrm{~cm}$ ). DBPs such as $B L I, B D I, B C I, A R E A$ and $A U P P$ were then calculated at each point of the database. SPSS statistical analysis software was used to correlate $M_{R}$ of

Table 2. Summary of statistical analysis of the research database

\begin{tabular}{|c|c|c|c|c|c|c|c|c|c|c|}
\hline \multicolumn{2}{|c|}{$\begin{array}{l}\text { Type of } \\
\text { statistics }\end{array}$} & $\begin{array}{c}D_{0}^{1} \\
\text { (micron) }\end{array}$ & $\begin{array}{c}D_{60}^{1} \\
\text { (micron) }\end{array}$ & $\begin{array}{c}D_{90}^{1} \\
\text { (micron) }\end{array}$ & $\begin{array}{c}D_{120}{ }^{1} \\
\text { (micron) }\end{array}$ & $S N_{e f f}$ & $S N_{r e q}$ & $\begin{array}{c}\text { Subgrade } M_{R} \\
(\mathrm{MPa})\end{array}$ & $\begin{array}{c}A C^{2} \\
(\mathrm{~mm})\end{array}$ & $\begin{array}{c}B S^{3} \\
(\mathrm{~mm})\end{array}$ \\
\hline \multicolumn{2}{|l|}{$n$} & 2453 & 2453 & 2453 & 2453 & 2453 & 2453 & 2453 & 2453 & 2453 \\
\hline \multicolumn{2}{|l|}{ Mean } & 198 & 81 & 53 & 37 & 5 & 5 & 71 & 171 & 258 \\
\hline \multicolumn{2}{|l|}{ Median } & 158 & 74 & 52 & 37 & 5 & 5 & 62 & 171 & 260 \\
\hline \multicolumn{2}{|c|}{ Std. Deviation } & 126.8 & 36.0 & 21.8 & 16.1 & 1.7 & 1.3 & 36.3 & 51.2 & 73.3 \\
\hline \multicolumn{2}{|l|}{ Range } & 728 & 183 & 126 & 90 & 7.5 & 6.5 & 277 & 321 & 411 \\
\hline \multicolumn{2}{|l|}{ Minimum } & 40 & 17 & 10 & 6 & 1.5 & 2.2 & 25 & 52 & 100 \\
\hline \multicolumn{2}{|l|}{ Maximum } & 768 & 200 & 136 & 96 & 9.0 & 8.7 & 302 & 373 & 511 \\
\hline \multirow{6}{*}{ Percentiles } & 60 & 185 & 84 & 57 & 41 & 5 & 6 & 69 & 186 & 280 \\
\hline & 70 & 224 & 96 & 65 & 46 & 6 & 6 & 80 & 199 & 302 \\
\hline & 80 & 275 & 112 & 72 & 51 & 7 & 6 & 93 & 212 & 322 \\
\hline & 85 & 323 & 120 & 76 & 54 & 7 & 7 & 103 & 221 & 332 \\
\hline & 90 & 389 & 133 & 82 & 58 & 7 & 7 & 119 & 234 & 344 \\
\hline & 95 & 492 & 150 & 90 & 64 & 8 & 8 & 143 & 255 & 367 \\
\hline
\end{tabular}

(1) $D_{x}$ is the deflection at distance of $x \mathrm{~cm}$ from FWD loading center.

(2) The total thickness of asphalt layers.

(3) The total thickness of base and sub-base layers. 
Table 3. Percentage of temperature correction factor applied to each FWD sensor (Fernando et al. 2001)

\begin{tabular}{cccc}
\hline $\begin{array}{c}\text { FWD } \\
\text { Sensor }\end{array}$ & $\begin{array}{c}A C \text { Thickness } \\
<75 \mathrm{~mm}\end{array}$ & $\begin{array}{c}A C \text { Thickness } \\
75 \mathrm{~mm}-125 \mathrm{~mm}\end{array}$ & $\begin{array}{c}A C \text { Thickness } \\
>125 \mathrm{~mm}\end{array}$ \\
\hline$D_{0}$ & 0 & 100 & 100 \\
$D_{30}$ & 0 & 45 & 62 \\
$D_{60}$ & 0 & 12 & 34 \\
$D_{90}$ & 0 & 5 & 10 \\
\hline
\end{tabular}

subgrade and $S N_{\text {eff }}$ of pavement with deflection basin parameters. Subgrade $M_{R}$ and pavement $S N_{\text {eff }}$ values were determined according to AASHTO (1993) design method. These two parameters were considered as dependent variables and DBPs were assumed as independent variables in the statistical analysis. The database was inserted into SPSS software and were divided randomly into $80 \%$ and $20 \%$ divisions. The first part was used to develop the models of $M_{\mathrm{R}}$ and $S N_{\text {eff }}$, while the second part (i.e. $20 \%$ ) was used for their validation purposes.

\section{Comparison of AASHTO (1993) versus current models}

Several models were developed by researchers using deflection basin parameters without using any layer thicknesses. In this research, current $S N_{\text {eff }}$ and $M_{R}$ models were reviewed and their correlation with AASHTO (1993) results were calculated.

\section{1. $S N_{\text {eff }}$ models}

Many researchers have studied the relationship between $S N_{\text {eff }}$ and DBPs. Table 4 reports five major models. As it can be seen, from this table the subgrade resilient modulus or deflections corresponding to subgrade responses (i.e. $\left.D_{900}, D_{1200}, D_{1500}\right)$ were used to calculate $S N_{\text {eff }}$ in many models. This justifies the dependency of $S N_{\text {eff }}$ to relative pavement/subgrade strength (Crook et al. 2012).
The database of this research were used to compare the above models for estimating $S N_{\text {eff }}$ parameters. In Table 4, parameters such as slope, intercept and $R^{2}$ of the simple linear regression in form of $y=a x+b$ (between each model and AASHTO (1993) proposed method) are reported. In Noureldin model (Noureldin 1993), it was assumed that the deflection $\left(d_{x}\right)$ at the distance of $r_{x}$ detects the subgrade response (deflection). This deflection is specified among FWD sensors when the equation $d_{x} \times r_{x}$ becomes maximum. $S N_{\text {eff }}$ is then calculated using subgrade deflection and its distance from the load center using the equation presented in Table 4 . The low $R^{2}$ and high intercept value prove the poor results obtained by Noureldin Model. $R^{2}$ coefficients of $S N_{\text {eff }}$, obtained from the other four models were better and were close to each other (compared with AASHTO values). Based on regression parameters (slope close to one, intercept close to zero and high $R^{2}$ ) COST 336 (1998) model showed to provide better estimate of $S N_{\text {eff }}$ among all the other models.

\subsection{Subgrade $M_{R}$ models}

Determining $S N_{\text {req }}$ according to AASHTO (1993) design guide, requires determination of $M_{R}$ of subgrade based on FWD deflection data. In FWD testing, geophones located at longer distances from the loading center measure deflections of the lower pavement layers. For example, if the stress is distributed with an angle of $45^{\circ}$, the geophone located at radial distance of $90 \mathrm{~cm}$ from the load center measures deflection at the depth of $90 \mathrm{~cm}$ from pavement surface. However, this assumption is not accurate because stress distribution varies at each layer due to changes in stiffness of the various layers. Accurate estimation of $M_{R}$ is of great importance due to the large impact on $S N_{\text {req }}$. Furthermore, $M_{R}$ should be determined using the same deflection basin, by which $S N_{\text {eff }}$ has been calculated. This is the correct method of comparing $S N_{\text {eff }}$

Table 4. Current $S N_{\text {eff }}$ prediction models based on only deflection data

\begin{tabular}{|c|c|c|c|c|c|}
\hline \multirow[b]{2}{*}{ Equation } & \multirow[b]{2}{*}{ Model Parameters } & \multicolumn{3}{|c|}{ Statistical characteristic } & \multirow{2}{*}{ References } \\
\hline & & $a$ & $b$ & $R^{2}$ & \\
\hline$S N_{e f f}=\frac{\left(4 r_{x}^{2}-36\right)^{1 / 2}}{17.234\left(r_{x} \cdot D_{x}\right)^{1 / 3}}$ & $R_{x}$ (in), $D_{x}$ (in) & 0.250 & 2.524 & 0.639 & Noureldin (1993) \\
\hline$S N_{\text {eff }}=0.0182 l_{0} \times \sqrt[3]{E_{s g}}$ & $l_{0}(\mathrm{~cm}), E_{S G}(\mathrm{MPa})$ & 0.478 & 1.724 & 0.838 & Hoffman (2003) \\
\hline$S N_{e f f}=1.69+\left(\frac{842.8}{D_{0}-D_{1500}}\right)-\left(\frac{42.94}{D_{900}}\right)$ & $D_{0}, D_{900}, D_{1500}$ (in) & 1.034 & -0.529 & 0.848 & COST 336 (1998) \\
\hline$S N_{\text {eff }}=13.5-6.5 \times \log D_{0}+3.7 \times \log D_{900}$ & $D_{0}, D_{900}$ (micron) & 0.269 & 2.588 & 0.757 & Jameson (1993) \\
\hline$S N_{\text {eff }}=e^{5.12} A U P P^{-0.78} B L I^{0.31}$ & $A U P P, B L I$ (micron) & 0.457 & 2.588 & 0.827 & Schnoor and Horak (2012) \\
\hline
\end{tabular}


with $S N_{\text {req }}$ and $S C I$ determination on each point of the pavement. It should be noted that $M_{R}$ of subgrade, resulted from back-calculation analysis must be corrected by a factor of 0.33 in accordance with AASHTO (1993) method so that it could be considered equivalent to $M_{R}$ obtained in laboratory. Table 5 presents some models of $M_{R}$ estimation based on DBPs. Similar to $S N_{\text {eff }}$ models analysis, $R^{2}$ coefficient and parameters of simple linear regression between $M_{R}$ at each model and AASHTO (1993) are represented. In these models, deflections at $90 \mathrm{~cm}$ and further distances from the load center were used to calculate $\mathrm{M}_{\mathrm{R}}$ of subgrade. In Horak model (Horak 1987), deflection at $180 \mathrm{~cm}$ from the load center (instead of $200 \mathrm{~cm}$ ) was used to calculate $M_{R}$ values, because this is the farthest deflection in the database. There were no significant relationship between AASHTO (1993) and Horak (1987) results. In the research database, the deflections located at 60 and $90 \mathrm{~cm}$ from load center were often used to calculate $M_{R}$ of subgrades (this is described in the following sections) while Horak (1987) model uses $D_{200}$ in the model. This issue reduced the accuracies of Horak (1987) model. In Table 5, one of the Washington State models which used the deflection at $90 \mathrm{~cm}$ (radial distance) showed the best correlation (i.e. $R^{2}=0.76$ ).

\section{Development of pavement $S N_{\text {eff }}$ model}

A correlation analysis was conducted with the aim of understanding relationship between DBPs and $S N_{\text {eff }}$ obtained from AASHTO (1993) method (see Table 6). As it can be seen in this table, AREA is directly related to
$S N_{\text {eff }}$ and the others had inverse relationship. Moreover, it can be concluded that parameters such as $D_{0}, B L I$ and $A U P P$ showed better correlations with $S N_{\text {eff: }}$ Table 6 also indicates that all parameters have non-linear relationship with $S N_{\text {eff: }}$ Therefore, it can be resulted that DBPs in nonlinear model can provide a better model to show the variation of dependent variable $\left(S N_{e f f}\right)$.

Figure 3 represents $S N_{\text {eff }}$ variation versus central deflections $\left(D_{0}\right)$. As it can be seen, the trend of $D_{0}$ shows a non-linear relationship. This figure also indicates the scattering of $D_{0}$ and $S N_{\text {eff }}$ in the database.

Regression analysis in SPSS software was performed using AASHTO (1993), $S N_{\text {eff }}$ as the dependent variable and parameters presented in Table 6 as the independent ones. From this statistical analysis, main six regression models were developed using $80 \%$ of data as presented in Table 7. The first three models indicate the effect of each DBP to predict $S N_{\text {eff }}$.

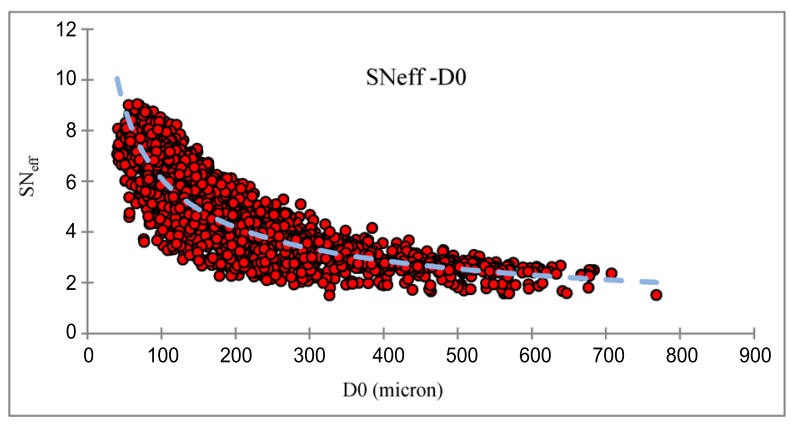

Fig. 3. $S N_{\text {eff }}$ variation with $D_{0}$

Table 5. Models of subgrade resilient modulus based on DBPs

\begin{tabular}{|c|c|c|c|c|c|}
\hline \multirow{2}{*}{ Equation } & \multirow{2}{*}{ Model Parameters } & \multicolumn{3}{|c|}{ Statistical characteristic } & \multirow{2}{*}{ References } \\
\hline & & $a$ & $b$ & $R^{2}$ & \\
\hline $\log E_{S G}=9.727-\log D_{200}$ & $\begin{array}{l}E_{S G}(\mathrm{~Pa}), D_{200} \\
\quad \text { (micron) }\end{array}$ & 0.037 & 8520 & 0.182 & Horak (1987) \\
\hline$E_{S G}=-371+0.00671\left(\frac{2 p}{D_{900}+D_{1200}}\right)$ & \multirow{3}{*}{$\begin{array}{c}E_{S G} \text { (psi) } \\
P(\mathrm{lb} .) \\
D_{900} \text { (in) } \\
D_{1200} \text { (in) }\end{array}$} & 0.186 & 2707.2 & 0.696 & \multirow{3}{*}{ Zhang et al. (2003) } \\
\hline$E_{S G}=-198+0.00577\left(\frac{p}{D_{1200}}\right)$ & & 0.129 & 4746.6 & 0.544 & \\
\hline$E_{S G}=-466+0.00762\left(\frac{p}{D_{900}}\right)$ & & 0.2172 & 1779.2 & 0.760 & \\
\hline
\end{tabular}

Table 6. Correlation factor of independent variables with $S N_{\text {eff }}$

\begin{tabular}{l|c|c|c|c|c|c|c}
\hline \multicolumn{1}{c|}{ Parameter } & $D_{90}$ & AUPP & AREA & BDI & BCI & $B L I$ & $D_{0}$ \\
\hline Correlation Factor & -0.111 & -0.818 & 0.621 & -0.778 & -0.702 & -0.817 & -0.783 \\
\hline Relationship & N.L & N.L & N.L & N.L & N.L & N.L & N.L \\
\hline
\end{tabular}


Table 7. Regression models developed to determine $S N_{\text {eff }}$

\begin{tabular}{c|l|c|c|c|c|c|c}
\hline \multirow{2}{*}{ No. } & \multicolumn{2}{|c|}{ Models } & \multicolumn{3}{c|}{$80 \%$ data } & \multicolumn{4}{c}{$20 \%$ data } \\
\cline { 3 - 8 } & \multicolumn{1}{|c|}{$a$} & $b$ & $R^{2}$ & $a$ & $b$ & $R^{2}$ \\
\hline 1 & $62.245 \times D_{0}^{-0.503}$ & 1.026 & -0.132 & 0.728 & 1.026 & -0.153 & 0.745 \\
\hline 2 & $0.000243 \times A R E A^{1.565}$ & 1.000 & 0.018 & 0.675 & 1.013 & -0.058 & 0.677 \\
\hline 3 & $35.473 \times A U P P^{-0.389}$ & 1.021 & -0.099 & 0.864 & 1.015 & -0.091 & 0.864 \\
\hline 4 & $34.171 \times D_{0}^{-0.638} \times D_{90}^{0.33}$ & 1.002 & -0.032 & 0.876 & 0.996 & -0.012 & 0.878 \\
\hline 5 & $4.181 \times A U P P^{-0.334} \times A R E A^{0.293}$ & 1.024 & -0.098 & 0.872 & 1.019 & -0.091 & 0.871 \\
\hline 6 & $28.007 \times A U P P^{-0.22} \times B L I^{-0.17}$ & 0.944 & -0.093 & 0.868 & 0.942 & -0.096 & 0.868 \\
\hline
\end{tabular}
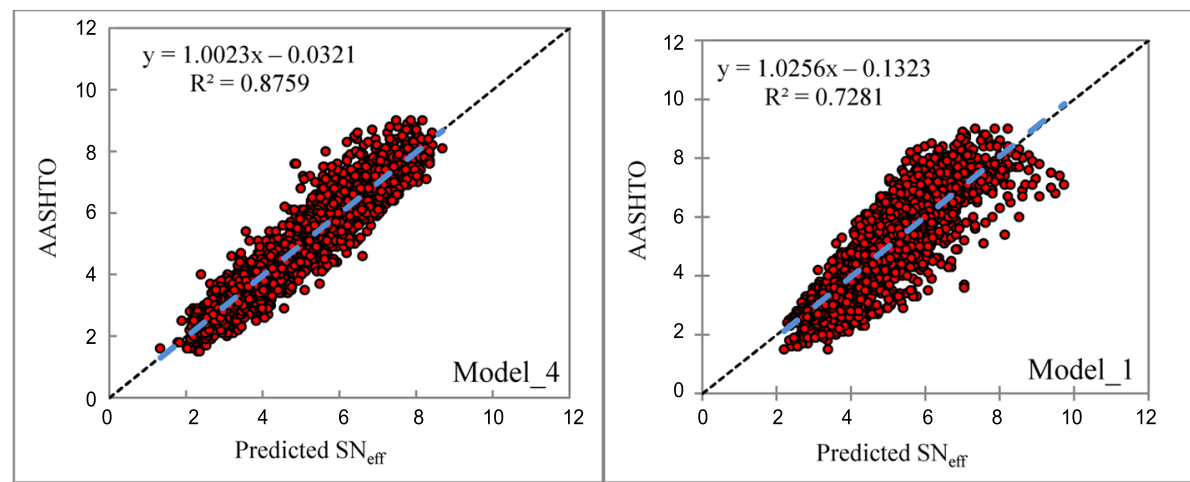

Fig. 4. Variation of predicted $\mathrm{SN}_{\text {eff }}$ versus AASHTO (1993) observed $S N_{\text {eff }}$

For comparison purposes, the predicted $S N_{e f f}$ (determined from the models) versus observed $S N_{\text {eff }}$ (AASHTO (1993) method) were drawn and their simple linear regression parameters were determined. For validation purposes, $S N_{\text {eff }}$ values were calculated using $20 \%$ data (this portion did not participate in model development) and compared with AASHTO (1993) method in the same way. As it can be seen in the first three models, the strength of $D_{0}$ and $A U P P$ parameters to estimate $S N_{\text {eff }}$ is more than AREA. The combination of the parameters were then used in other models to enhance their accuracy. For example, Model No. 4 was developed using $D_{0}$ and $D_{90}$. Adding $D_{90}$ as the effects of lower layers improved Model No. 4 compared with Model No. 1. AUPP was accompanied by $A R E A$ and BLI parameters to develop the above last two models. Among the six models presented in Table 7, Models No. 4 and 5 showed the best results. Model No. 4, due to its better regression parameters (slope close to one, intercept close to zero and higher $R^{2}$ ) was selected as the best model for estimating $S N_{\text {eff }}$. This model was also better validated in $20 \%$ of data, compared with Model No. 5. Figure 4 shows variations of predicted $S N_{\text {eff }}$ obtained from Models No. 1 and 4 versus AASHTO (1993) $S N_{\text {eff: }}$ The data points were better concentrated around the line with $45^{\circ}$ angle in Model 4.

\section{Development of subgrade $M_{R}$ model}

The initial step in model development was to perform correlation analysis between DBPs and AASHTO (1993) $M_{R}$ using SPSS software. Correlations reported in Table 8 show that the relationship becomes stronger with increasing distance from the load center (up to $60 \mathrm{~cm}$ ) and then the relationship decreased gradually. $D_{0}$ shows a correlation factor of 0.54 because it describes pavement and subgrade structural behaviour. As expected, BLI, representing upper layer structural response, had the lowest relationship with $M_{R}$ of subgrade. $B C I$ representing subbase and subgrade behaviour had stronger relationship, compared with $B L I$ and $B D I$.

With respect to Table 8 , the best correlation belonged to inversed deflections at distance of $60 \mathrm{~cm}$ from the load center. As it can be seen in this table, inverse deflections showed linear relation with $M_{R}$, while the other parameters showed non-linear relationship.

Table 9 shows the best models developed based on deflection basin parameters in SPSS Software. The procedure for developing the model was similar to those expressed in $S N_{\text {eff }}$ models.

The model using $D_{60}$ was more reliable for estimating $M_{R}$ of subgrade. Hence, Model No. 1 (with determination coefficient of 0.92 ) was selected as the most 
Table 8. Correlation of independent variables with $M_{R}$

\begin{tabular}{l|c|c|c|c|c|c|c|c|c|c|c}
\hline \multicolumn{1}{c|}{ Parameter } & $\frac{1}{D_{60}+D_{90}}$ & $\frac{1}{D_{90}}$ & $\frac{1}{D_{60}}$ & $D_{150}$ & $D_{120}$ & $D_{90}$ & $D_{60}$ & $B C I$ & $B D I$ & $B L I$ & $D_{0}$ \\
\hline Correlation Factor & 0.953 & 0.867 & 0.961 & -0.668 & -0.724 & -0.79 & -0.796 & -0.593 & -0.431 & -0.328 & -0.539 \\
\hline Relationship & L & L & L & N.L & N.L & N.L & N.L & N.L & N.L & N.L & N.L \\
\hline
\end{tabular}

Table 9. The developed models to determine $M_{R}$ of subgrade

\begin{tabular}{c|c|c|c|c|c|c|c}
\hline \multirow{2}{*}{ No. } & \multirow{2}{*}{ Models } & \multicolumn{3}{|c|}{$80 \%$ data } & \multicolumn{3}{c}{$20 \%$ data } \\
\cline { 2 - 7 } & & $a$ & $b$ & $R^{2}$ & $a$ & $b$ & $R^{2}$ \\
\hline 1 & $4545.04 \times\left(1 / D_{60}\right)+1.76$ & 1.003 & -0.171 & 0.921 & 0.999 & 0.101 & 0.927 \\
\hline 2 & $2502.28 \times\left(1 / D_{90}\right)+13.24$ & 0.997 & 0.169 & 0.753 & 1.001 & -0.230 & 0.754 \\
\hline 3 & $7509.77 \times\left(1 /\left(D_{60}+D_{90}\right)\right)+2.8$ & 1.007 & -0.482 & 0.911 & 1.010 & -0.761 & 0.918 \\
\hline
\end{tabular}

appropriate model to predict $M_{R}$ of subgrade. This model was also validated accurately in $20 \%$ of the data due to low variation in linear regression parameters.

\section{Implementation of models at network-level pavement management}

Based on results obtained in this research, two regression models were developed to predict $S N_{\text {eff }}$ of pavements and $M_{R}$ of subgrades. These models are presented in Eqns (2) and (3).

$$
\begin{gathered}
S N_{e f f}=34.171 \times D_{0}^{-0.638} \times D_{90}{ }^{0.33} ; \\
M_{R}=4545.04 \times\left(1 / D_{60}\right)+1.76 .
\end{gathered}
$$

Subgrade modulus obtained from Eqn 3 (together with traffic data) were used to calculate $S N_{\text {req }}$ according to AASHTO (1993) Pavement Design Guide. Finally, SCI was calculated based on Eqn (1).

Shoush-Andimeshk roadway was selected to describe how the presented method should be applied for decision making at network-level pavement management. SCI values in the selected road were calculated at each point loaded by FWD. These values can be significantly varied point to point along the pavement. Hence, these could not be suitable to determine the type of M\&R meth- ods at network-level pavement management. To solve this problem, pavement should be divided into homogenous structural sections. This issue was performed by drawing Cumulative Difference Graph of $D_{0}$ versus road change in Figure 5. The sectioning method was derived from the method described in Appendix J of AASHTO Pavement Design Guide (AASHTO 1993).

Each uniform slope in Figure 5 indicates a homogenous pavement structural section. The five sections can be separated based on slope variations. As it can be seen in this figure, Sections 2 and 4 due to their high positive slopes (deflections at these sections were higher than the mean deflection of the whole pavement) were considered weaker than the other sections. SCI can be averaged in homogenous sections so that to decide which M\&R methods should be assigned to those. Table 10 represents the mean SCI values calculated using the proposed method and that of AASHTO (1993).

As it can be seen in Table 10, SCI differences between the two methods were negligible in all sections. Sections 1,3 and 5 have $S C I \geq 1$ in both methods. Hence, preservation activity can be assigned to these sections. In Sections 2 and 4 where $S C I<1$ indicates the need for rehabilitation activity. After calculating SCI in homogenous structural sections, engineering judgment

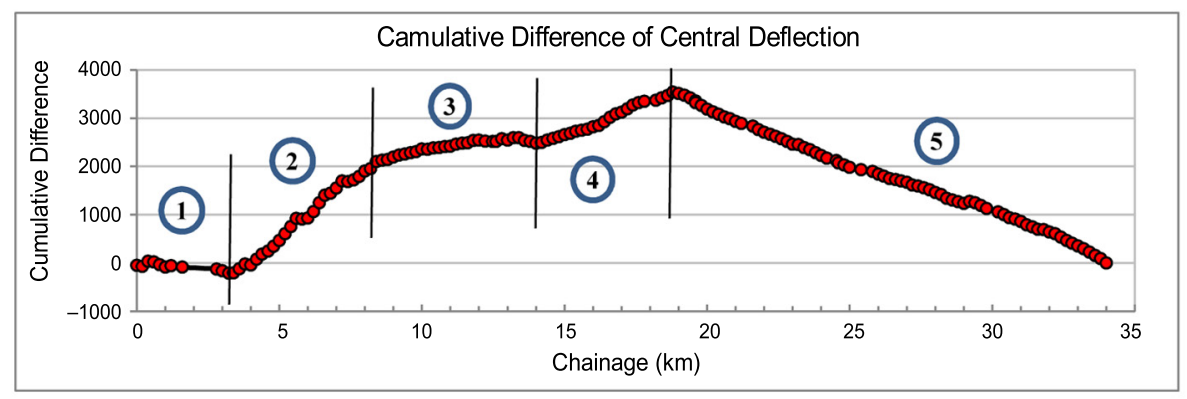

Fig. 5. Cumulative differences of $D_{0}$ at Ahvaz-Shoush roadway 
Table 10. Comparison of $S C I$ values obtained from proposed method and AASHTO (1993)

\begin{tabular}{c|c|c|c|c|l}
\hline \multirow{2}{*}{ Sec. } & Start & End & \multicolumn{2}{|c|}{ SCI } & \multirow{2}{*}{\begin{tabular}{c} 
M\&R of \\
\cline { 2 - 5 }
\end{tabular}} \\
\cline { 2 - 5 }$(\mathrm{km})$ & AASHTO & Models & Proposed Method \\
\hline 1 & 0 & 3.4 & 1.4 & 1.2 & preservation \\
\hline 2 & 3.4 & 8.4 & 0.8 & 0.8 & rehabilitation \\
\hline 3 & 8.4 & 14 & 1.1 & 1 & preservation \\
\hline 4 & 14 & 19 & 0.9 & 0.9 & rehabilitation \\
\hline 5 & 19 & 34 & 1.6 & 1.6 & preservation \\
\hline
\end{tabular}

and considering operational restrictions could help road authorities to finalize sections that should be evaluated at project level.

The proposed method is of great importance at the road network where no previous PMS was implemented. In these conditions, it is necessary to identify current pavement conditions with methods that can be performed with low cost and at a rather short timing.

\section{Conclusions}

In this research, $S C I$ was suggested for network-level pavement management of flexible pavements. $S C I$ determination requires $S N_{\text {eff }}$ and $S N_{\text {req }}$ (based on AASHTO (1993) method). This study focused on developing two regression models to predict $S N_{\text {eff }}$ and $M_{R}$. Models were developed based on only DBPs and without having knowledge of pavement layers thicknesses. The findings can be summarized as it follows:

1. COST Model for estimating $S N_{\text {eff }}$ was the best among the other models due to its better linear regression parameters.

2. Although $A U P P$ and $A R E A$ parameters are calculated using the same four initial deflections (up to $90 \mathrm{~cm}$ ), SNeff variations can better be predicted using $A U P P$. This parameter with $R_{2}$ of 0.82 had the strongest relationship with $S N_{\text {eff }}$ and was the best DBPs.

3. The significant result of this study was to calculate $S N_{\text {eff }}$ and $M_{R}$ using the same deflection basin that belonged to a certain point of the pavement. This resulted in a better comparison between $S N_{\text {eff }}$ and $S N_{\text {req }}$ in order to determine $S C I$ values.

4. Subgrade $M_{R}$ had the best correlation with the invers of deflection at $60 \mathrm{~cm}$ distance from load center with $R_{2}$ of more than 0.9 . Therefore, it was predictable that among current $M_{R}$ models, the one that uses $D_{90}$ should be the best with $R_{2}=0.76$ in comparison with those that used farther deflections to develop MR model.

5. Two regression models were developed to predict $S N_{\text {eff }}$ and subgrade $M_{R}$ without using layer thicknesses. The accuracy of these models was greater than the current models reviewed.

6. The best approach in implementing this method is to divide road network into homogenous structural sections using cumulative difference method of maxi- mum deflections $\left(D_{0}\right)$. Average $S C I$ values in each section indicate whether the section is structurally deficient (that needs rehabilitation activities or it requires preservation activities only).

\section{References}

American Association of State Highway and Transportation Officials. (AASHTO). 1993. AASHTO guide for design of pavement structures. Washington D.C., USA.

Aavik, A. 2003. Methodical basis for the evaluation of the pavement structural strength in Estonian pavement management system: $\mathrm{PhD}$ thesis. Tallinn Technical University, Tallinn.

Bryce, J.; Flinstch, G.; Katicha, S.; Diefenderefer, B. K. 2013. Enhancing network-level decision making through the use of a structural capacity index, Transportation Research Record 2366: 64-70. https://doi.org/10.3141/2366-08

Chowdhury, T.; Shekaran, R. A.; Diefenderefer, B. K. 2012. Implementation of network-level falling weight deflectometer survey, Transportation Research Record 2304: 3-9. https://doi.org/10.3141/2304-01

COST 336. 1998. Falling weight deflectometer: information gathering report. Task Group 2 FWD at network level. Final draft report.

Crook, A. L.; Montgomery, S. R.; Guthrie, W. S. 2012. Use of falling weight deflectometer data for network-level flexible pavement management, Transportation Research Record 2304: 75-85. https://doi.org/10.3141/2304-09

Dasari, K. V. 2013. Deflection based condition assessment for rolling wheel deflectometer at network-level: MSc thesis. Louisiana State University, USA.

Fernando E. G.; Liu, W.; Ryu, D. 2001. Development of a procedure for temperature correction of back-calculated ac modulus. Texas Department of Transportation Research and Technology Implementation Office, USA. No FHWA/ TX-02/1863-1.

Hoffman, M. S. 2003. Direct method for evaluating structural needs of flexible pavements with falling weight deflectometer deflections, Transportation Research Record 1860: 41-47. https://doi.org/10.3141/1860-05

Horak, E.; Maina, J. W.; Van Wijk, I.; Hefer, A.; Jordaan, G.; Olivier, P.; de Bruin, P. W. 2009. Revision of the South African pavement design method. Draft Contract Report, No. SANRAL/SAPDM/B-2/2009-01.

Horak, E. 1987. The use of surface deflection basin measurements in the mechanistic analysis of flexible pavements, in Proceedings of Sixth International Conference "Structural Design of Asphalt Pavements”, 13-17 July 1987, University of Michigan, Ann Arbor, Michigan, USA, 1: 990-1001.

Jameson, G. W. 1993. Development of procedures to predict structural number and subgrade strength from falling weight deflectometer deflections. ARRB TR, Vermont South, Victoria, Australia.

Kim, M. Y.; Kim, D. Y.; Murphy, M. R. 2013. Improved method for evaluating the pavement structural number with falling weight deflectometer deflections, Transportation Research Record 2366: 120-126. https://doi.org/10.3141/2366-14

Noureldin, A. S. 1993. New scenario for back calculation of layer moduli of flexible pavements, Transportation Research Record 1384: 23-28.

Pavement Interactive. 2010. Deflection based non-destructive pavement analysis [online], [cited 10 April 2015]. Available from Internet: http://www.pavementinteractive.org/ article/deflection-based-nondestructive-pavement-analyses

Schnoor, H.; Horak, E. 2012. Possible method of determining structural number for flexible pavements with the falling 
weight deflectometer, in Proceedings of the $31^{\text {th }}$ Southern African Transport Conference (SATC 2012), 9-12 July 2012, Pretoria, South Africa, 94-109.

Shahin, M. Y. 2005. Pavement management for airports, roads and parking lots. $2^{\text {nd }}$ ed. New York: Springer. $572 \mathrm{p}$.

Stubstad, R.; Carvalho, R.; Briggs, R.; Selezneva, O. 2012. Simplified techniques for evaluation and interpretation of pavement deflections for network-level analysis: guide for assessment of pavement structural performance for PMS application. US Department of Transportation, Washington, D. C., USA. Publication No. FHWA-HRT-12-025.

Zhang, Z.; Claros, G.; Manuel, L.; Damnjanovic, I. 2003. Evaluation of the pavement structural condition at network level using falling weight deflectometer (FWD), Data, presented at $82^{\text {nd }}$ Annual Meeting of the Transportation Research Board, 12-16 January 2003, Washington, D.C. USA.

Amir KAVUSSI. PhD, Associated Professor, Tarbiat Modares University, Department of Civil and Environmental Engineering, Tehran, Iran. Research interests: Asphalt Mixtures and Technology, Pavement Management System (PMS), Non-Destructive Test (NDT).

Mojtaba ABBASGHORBANI. PhD candidate at Road \& Transportation Engineering, Tarbiat Modares University, Department of Civil and Environmental Engineering, Tehran, Iran. Research interest: Pavement Management System (PMS), Non-Destructive Test (NDT), Performance Tests.

Fereidoon MOGHADAS NEJAD. PhD, Associated Professor, Amirkabir University of Technology, Department of Civil and Environmental Engineering, Faculty of Geotechnical and Transportation Engineering, Tehran, Iran. Research interest: Asphalt Pavement Modelling, Pavement Management System (PMS), Non-Destructive Test (NDT).

Armin BAMDAD ZIKSARI. MSc in Geotechnical Engineering, Technical Soil and Mechanics Laboratory of Ministry of Road and Urban Development, Tehran, Iran. Research interest: Pavement Management System (PMS), Non-Destructive Test (NDT), FEM Modelling. 